\title{
METHODOLOGY DEVELOPMENT FOR DESIGNING FLOOD CHANNELS AS RECREATIONAL WATERWAYS
}

\author{
CAGRI CIMEN \& ANIL OLGAC \\ Yüksel Proje Uluslararası A.Ş., Turkey
}

\begin{abstract}
Floods are the most damaging secondary natural disaster, after earthquakes. In this sense, in order to ensure the flood safety of the rivers especially in the city center, rehabilitation activities are carried out and other purposes are not generally taken into consideration. In parallel with this, as a consequence of dense housing in metropolitan areas in our country, the landscape in the cities being inadequate and the need for recreational common areas where people can relax is increasing. When all this is taken into account, it is thought that rehabilitation of the creeks would be possible, as well as creating breathable areas. Generally accepted practice for the river rehabilitation project is just discharging the flood with adequate geometry and dimension of channel, while a recreational feature will also be provided with this study. It is foreseen that conventional calculation methods will be inadequate for this study. To provide visually more livable environment around the creek bands; a clean and steady water image will be aimed at normal seasons (except during flooding) in the reclamation channel. Necessary hydraulic structures (like embankments, etc.) and chutes suiting the site topography will be placed in the channel for this target. The tributary creeks connected to the main river will also be included in the calculations as part of the overall design. At the same time, trying to create a steady and clean water image requires the developing of economically viable solutions for the operation of rehabilitated river. In this sense, it is thought that creek water will not be suitable due to the sediment transported by the creek for the desired steady water condition in the channel. Hydraulic structures will be designed to trap these deposits and this design will be implemented as part of the whole.
\end{abstract}

Keywords: flood, creek rehabilitation, recreational water channel, water image, flood safety, flood modelling.

\section{INTRODUCTION}

Generally, rehabilitations are being made to ensure the flood safety of the creeks into the city, and other purposes are often overlooked. As an aim of the project, it is possible to create habitable areas around the flood structures as well as providing the flood safety via the rehabilitation of the creeks.

In order to ensure that the creek band is more livable in terms of the visual sense, it was aimed to create a clean and stagnant water image within the flood channel in normal season (except flood seasons). Thus, situating the necessary hydraulic structures (embankments, etc.) into the channel, setting the chutes based on the topography were required. The tributaries connected to the main channel were also included in the calculations as part of the whole design. Besides, designing of a stagnant and clean water image, it's also required to find economical solutions during the operation of the rehabilitated creek. In this sense, it was assessed that water into the creek would not be suitable due to the sediment for the desired stagnant and clean water into the channel. In order to trap the sediment, hydraulic structures have been designed.

The project does not only have the hydraulic structures on the main channel and the tributaries, but also recreational environment arrangements have been designed. Thus, it is aimed to make this abandoned valley as a part of the city. 
In this framework, as shown in Fig. 1, the opportunities and the threats have been assessed with dealing of the strengths and weakness aspects of the project with a SWOT analysis in the beginning of the project.

\section{PURPOSE AND DESIGN OF MAIN FLOOD CHANNEL}

The Valley Ankara Project is approximately $9 \mathrm{~km}$ long project planned to be constructed in the Valley Imrahor in Ankara, Turkish capital city, for the purposes of flood protection and recreation. Under the project, the Main Creek rehabilitation and the bed arrangement of tributaries flowing into the main creek will be carried on.

Within the scope of the main creek rehabilitation, it is necessary to take the creek into a proper channel section. For this purpose, many alternative sections have been evaluated for the channel section and the transverse embankments have been designed in order to make a continuous water image for recreational purposes. The embankments have been placed correspondingly based on the channel longitudinal slope, which is parallel to the existing ground topography. Also it has been aimed at creating a maximum water depth of $0.80 \mathrm{~m}$ at the upstream part of embankments, and a maximum value of $0.30 \mathrm{~m}$ at the downstream part. As a result of the hydraulic analyses made [3], [4], the tributaries of the rehabilitation channel with a $20 \mathrm{~m}$-wide bottom has been designed as cascading. Not only these cascades provide a sufficient section for floods, but they can also be used for recreative purposes by creating the pondlets giving a water image in the normal season (Fig. 2).

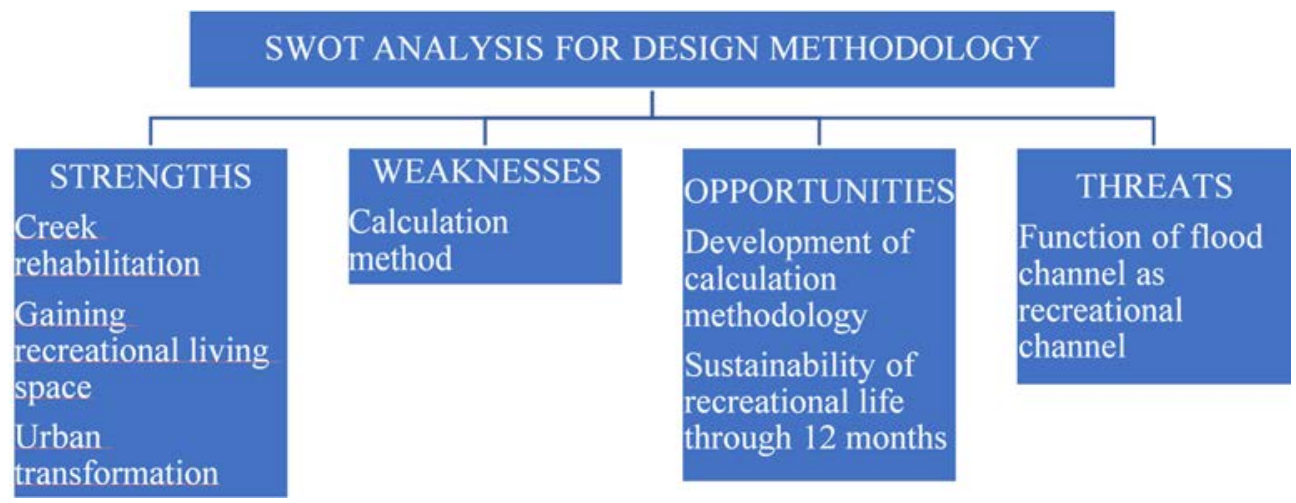

Figure 1: SWOT analysis for design methodology.

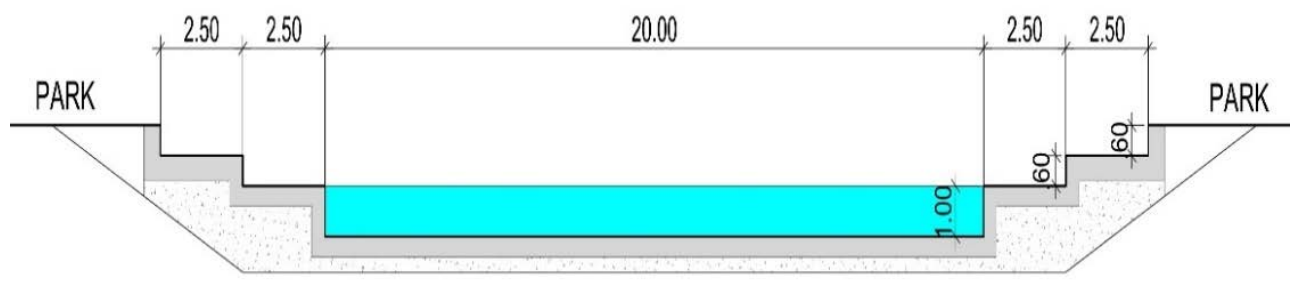

Figure 2: Main channel typical section. 


\subsection{Flood channel in normal season}

Except for flood season, the channel has been divided into parts with embankments in order to provide the continuity of water image demanded in the normal season. Each part has been assessed as a small artificial pondlet in itself. There will be a total of 99 parts separated with embankments over the main channel (Fig. 3).

In a $9 \mathrm{~km}$-long channel, it causes many big challenges to solve the cleaning problem of $90,000 \mathrm{~m}^{3}$ water to be required for 99 pondlets giving a water image for recreational purposes in dry seasons with a single filtration-circulation system. For this case, the identified requirements and effects have been determined as follows.

The size of mechanical chamber will be approximately $3,000 \mathrm{~m}^{2}$. Such a large volume occurs the problems of infrastructure and costs in the recreational area.

Due to the level difference in the corridor having an average slope of $0.5 \%$ between the beginning and end of the channel, there are several chutes along the channel. In this case, it will be necessary to install a filtration-circulation system with lines, whose the longest one is $4.5 \mathrm{~km}$. Additional measures will be needed to maintain the water flow rate in such long pipes.

Considering a water body as an installation means discharging and filling all water at the same time. It will take a long time to fill such a large water body with the main supply line and to discharge all water with a single line and it will cause to increase the size of pipes in the line. In addition, the management of whole water body from a mechanical center raises operational costs.

Considering the above-mentioned issues, it has been found a more sustainable approach to install a fragmented system in order to prevent the problems of implementation and cost to be caused by a single filtration-circulation system. Thus, the adaptation of the system with the existing infrastructure and the ease of intervention facilities also provide an advantage in terms of the costs and the system management.

For these reasons, 99 pondlets have been grouped in its own. In general, a total of 31 units of machinery chambers to circulate the water of minimum 3 pondlets into the channel after filtrating will be controlled from a single center by means of SCADA.
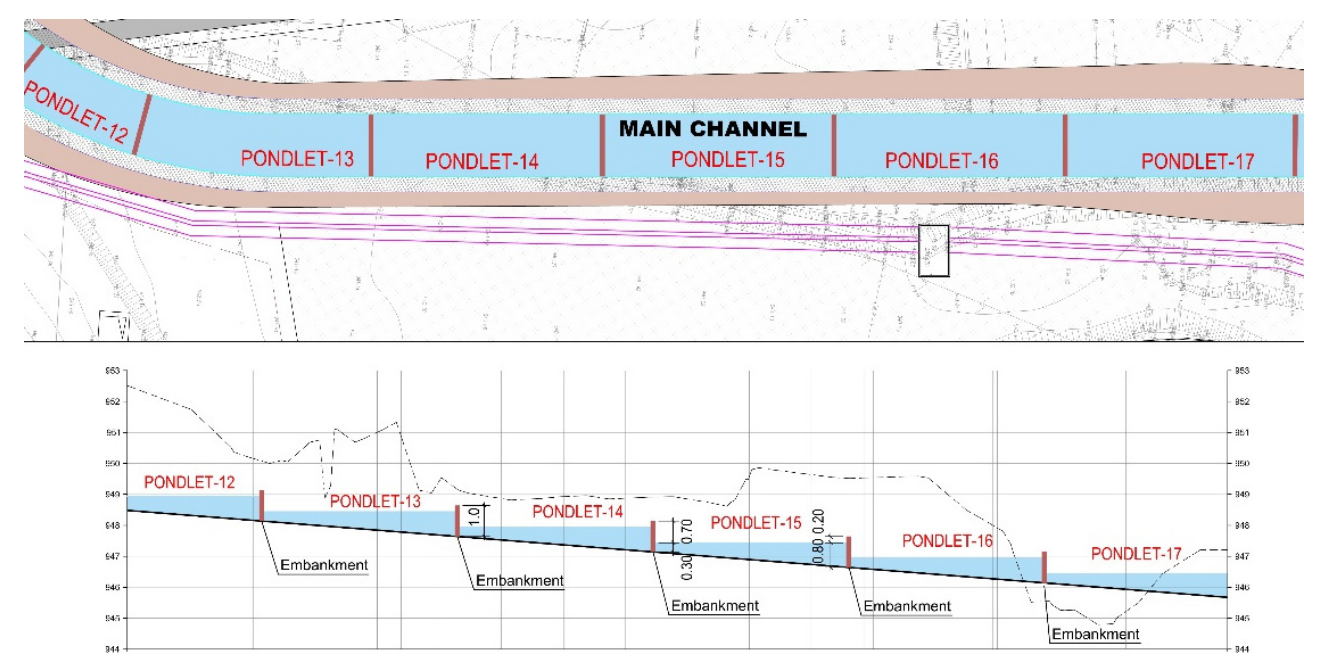

Figure 3: Setting the pondlets for water image into plan and profile. 




Figure 4: Plan example for filtration piping system of water into pondlets.

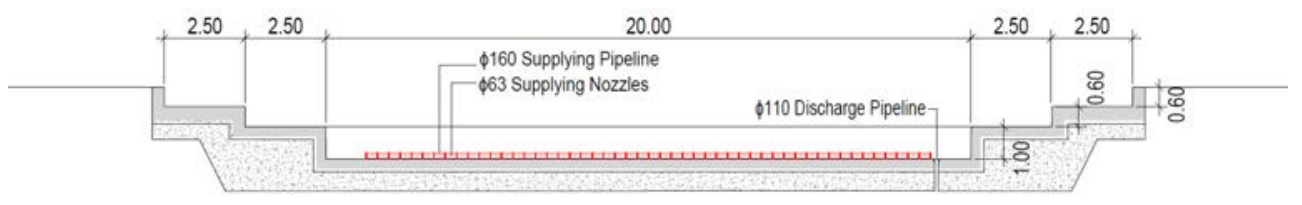

Figure 5: Cross-section for filtration piping into pondlets.

The necessary supplying nozzles for the circulation of each pondlet have been installed over the embankments. The operation of supplying into one group of pondlets is planned as to be filled of water weired over the embankment after the upstream pondlets. As can be seen from Figs 4 and 5; the suction lines are located at the bottom of pondlet which is having the lowest elevation at the end of the group.

The circulation period has been determined as 8 hours in the result of optimization study made for operational costs. It has been decided to select the 8-hour period in the night hours when the electricity rates are low. The whole system will be emptied for a certain period and re-filled with clean water.

\subsection{Flood channel in flood season}

Prior to all works, a 2D hydrodynamic modelling has been carried out to detect the damages to be created by floods [1]. As a result of the modelling, the expansion and damages of the flood have been determined and used as an input for the economy of the project.

Due to the large expansion of flood and the floods experienced even if they are lowfrequency in the recent past, a great portion of the project area is abandoned. In order to take this abandoned area that is closed to the city center (Fig. 6) into a daily living area, as a first step to make an attractive center, the flood hazard should be eliminated.

The flood water has to be safely conveyed via the channel. With this purpose, the water levels, water depths, and velocity profiles in case of occurring the flood flows with certain frequency, have been determined by running an analysis of 1D hydrodynamic modelling in the flood channel and then the adequacy of the section has been assessed [2]. The data required for the hydrodynamic modelling is provided in Fig. 7.

When dimensioning the channel and determining the longitudinal bottom slope, care has been taken for the fact that the section is adequate to safely convey the flood to the downstream without overflowing the channel section. For this purpose, alternatives of section 


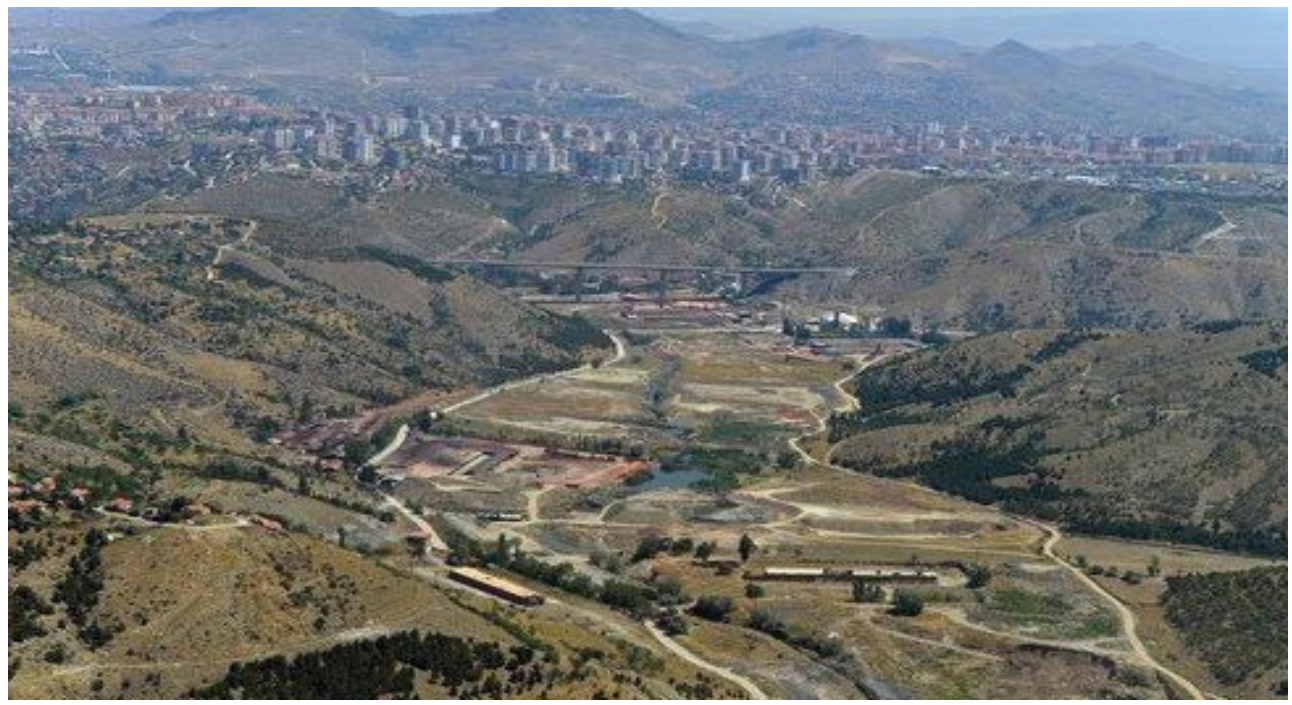

Figure 6: Picture of current view for project area.



Figure 7: Database for hydrodynamic modelling.

dimensions/geometries have been studied. In conclusion, a section having a $20 \mathrm{~m}$ wide bottom, and the cascaded tributaries has been designated.

The MIKE 11 model has been used within the scope of the 1D hydrodynamic modelling. A solution is found by considering the continuity and the conservation of momentum in software. It is used to calculate a water surface profile in the steady and unsteady gradually varied flow regimes. The MIKE 11 model can model a system divided into tributaries or one whole channel network as well as a single river. It has a modelling capacity of the water surface profiles of the supercritical, subcritical and mixed flow regimes. The model solves the 1D Saint Venant Equations to determine the time-dependent variations of the water levels and velocities. While one of the hydrodynamic equations, which the 1D Model uses during running, is used for the conservation of continuity, the other one is used for the conservation of momentum. These simplified equations are used by the model to calculate the conservations of continuity and momentum, being 2 basic principles of the 1D model, between the sections. See eqns (1) and (2). 


$$
\begin{gathered}
\frac{\partial A}{\partial t}+\frac{\partial Q}{\partial x}=q_{1}, \\
\frac{\partial Q}{\partial t}+\frac{\partial}{\partial x}(Q V+g A \bar{y})=g A\left(S_{o}-S_{f}\right)+V_{x} q_{1} .
\end{gathered}
$$

These equations are solved with the finite difference method by applying the Thomas algorithm. The hydrodynamic model calculations are performed to determine the flow rate and level values of water at the locations classified as Q-points and H-points along a river bed.

The H-points are provided at all sections and the Q-points are available in the middle of the automatically successive H-points and in the hydrodynamic structures.

Besides, the structures (bridges, energy dissipaters, culverts) existing on a stream are defined as Q-points and the water surface profiles and flow rates are calculated by solving after interchanging the momentum equation and the energy equation.

In the software, the Digital Elevation Model (DEM) created from the maps prepared in the GIS portal as a topographical background is used. After the identification of DEM into MIKE, flood water spreads, the locations having risk, and the velocities/depths of water at these locations are determined for varies of flood frequencies. The solution has been made for a total of $9 \mathrm{~km}$ long channel.

The 1D models have been established by means of placing the designed whole channel geometry on the digital land model as a map base.

In the 1D Model, the topography is defined by means of the sections taken perpendicular to the creek. The sections prepared perpendicularly to the flow direction along the riverbed are used to express the model parameters. The frequency of sectioning is determined by the terrain. The determinant factors are the variations in the sections and slopes of the riverbed, the variations of friction coefficient, and the interaction of superstructures, main channel and tributaries.

Within the scope of the 1D modelling studies, first of all, the sections well representing the terrain are taken on the created DEM. Under this study, the designed channel geometry is applied to each section. The 1D model is an efficient modelling tool in order to observe the water movement inside a channel and examine the conditions of the superstructures. The use of the 1D model for the spread of water overflowed a channel in a land is not sensitive enough in the urbanized regions. The use of 1D model for the open terrain, does not provide accurate results. Also, it is not possible to produce the backgrounds like velocity vectors, necessary for flood hazard areas via $1 \mathrm{D}$ model. In this respect, the evaluations up to a maximum water amount to flow through a channel are performed during the 1D model studies. In this study, as the aim is to keep water inside the channel, the 1D modelling either increases the solution speed or provides adequate accuracy.

The Courant number, obtained by considering the time and distance intervals, is used in order to determine whether the established model is stable. The Courant number calculated depending on the factors of speed, time and distance is important for a hydrodynamic modelling to give stable and consistent results numerically. Therefore, the Courant number should be lower than 1 .

It is necessary to define the boundary conditions in the model simulation. The peak flow rates calculated after hydrological studies have been defined as an upstream boundary condition and other tributary creeks are defined as point flow rates from the related connection points. In the downstream hydrodynamic conditions, the flood water level of $909 \mathrm{~m}$ has been defined as the water level. 


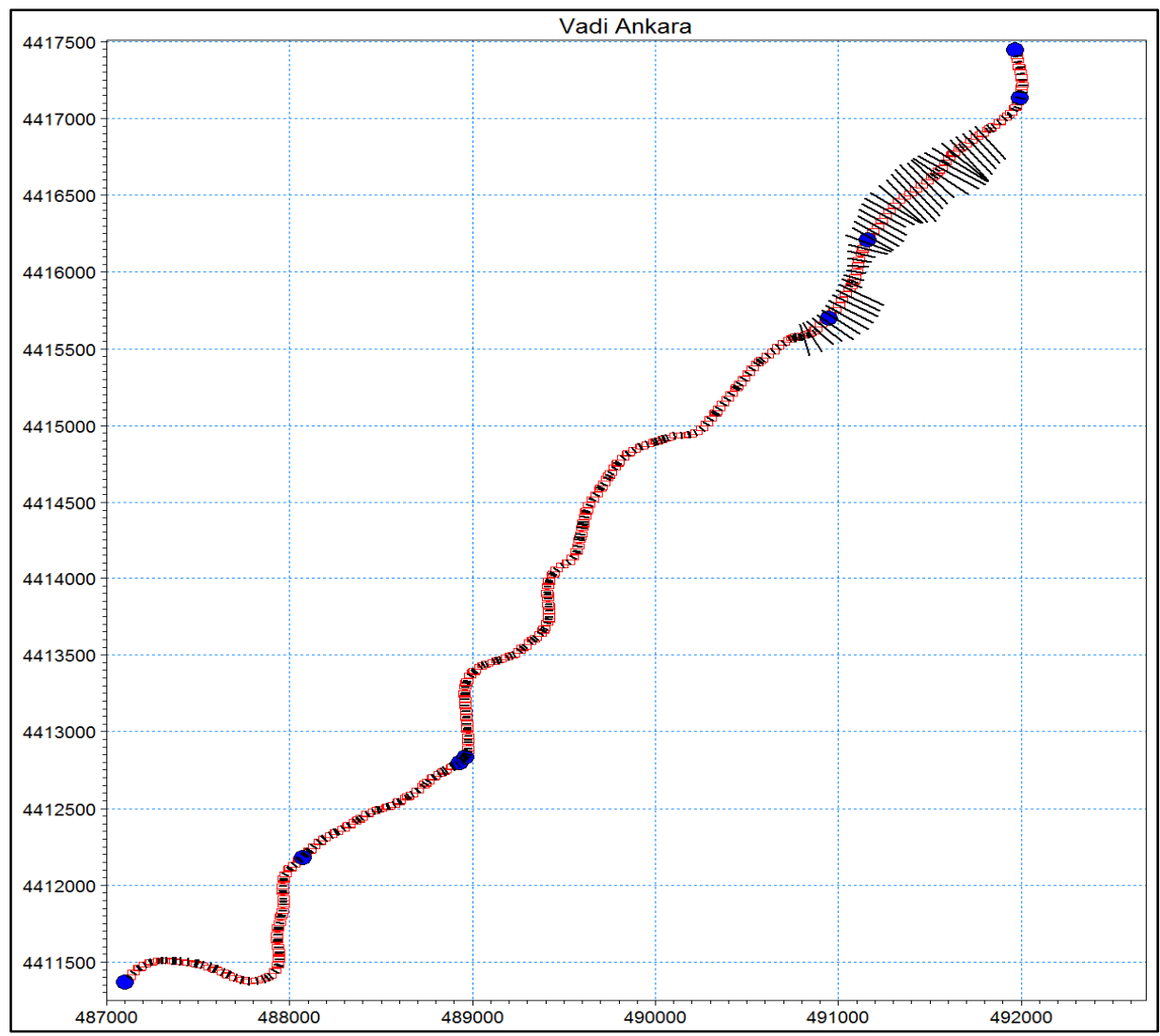

Figure 8: Plan of canal and section locations.

The coefficient of friction defined in the designed concrete channel has been selected as $\mathrm{n}=0.020$. Having not any expansion area and the analysis of flow only inside the channel rather than the flood area, the coefficient defined in the 1D model have an effect along the channel.

Only embankments are existing as a superstructure effecting the flow in the project area. The embankments have been determined into the model so as to best reflect the actual situation and their hydraulic effects studied.

While determining the embankments into the model, the initial conditions have been defined to give a $0.8 \mathrm{~m}$ height at the upstream side, and a $0.3 \mathrm{~m}$ height at the downstream side of each embankment. Due to this condition, the hydraulic model has been run as to be flooded in case of having full of water into the pondlets. This can be also defined as the worst scenario.

When reviewed the results of the studied model, it has been determined that no overflow for any flood recurrence frequency, the capacity of the channel with freeboard (eqn (3)) is sufficient, and the maximum velocity criteria $(5 \mathrm{~m} / \mathrm{s})$ has been obtained. It can be seen that the water surface from the profile shown in Fig. 9.

$$
\Delta \mathrm{h}=0.60+0.036 V h^{1 / 3}\left(\text { Freeboard for } Q_{100}\right) \text {. }
$$




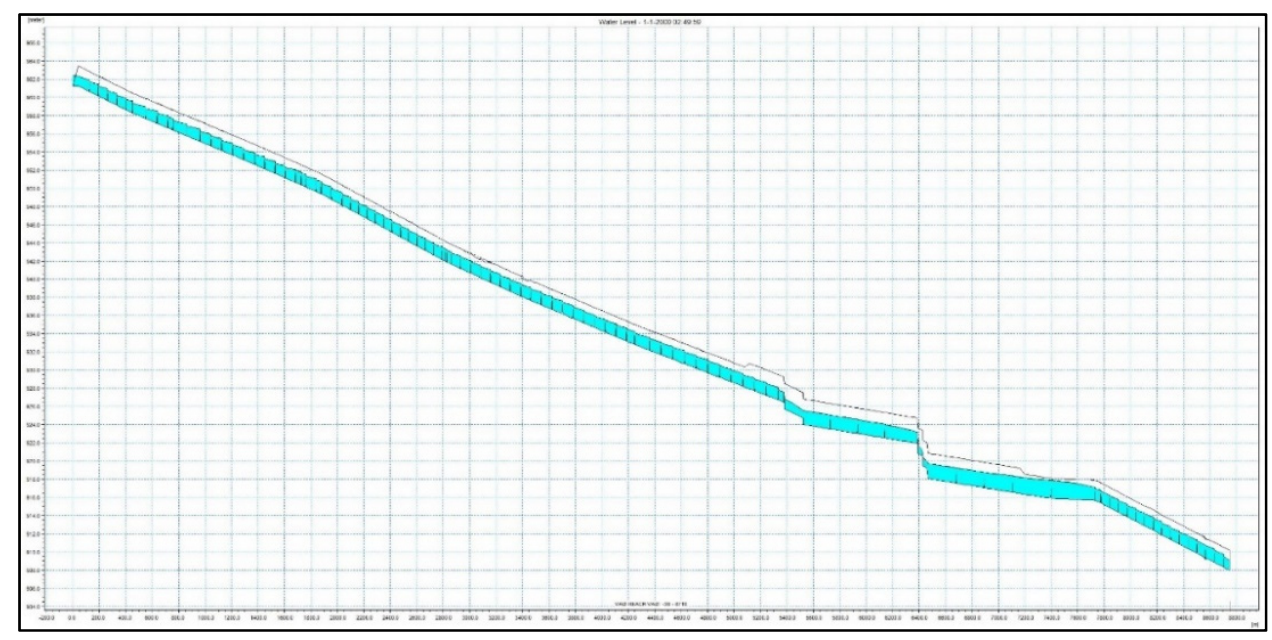

Figure 9: Results of 1D model-channel profile (Q500).

\section{TRIBUTARY CONNECTIONS-INTERCEPTOR PIPELINE-SEDIMENTATION}

There are 4 tributaries joining the Main Creek from different points on the right bank. Their names from upstream to downstream are Dolay Creek, Abaz Creek, Dut Creek, and Çaylak Creek.

Considering the direct connections of tributaries to the main channel, a sedimentation problem arises. The main channel shall have clean water image except for the flood duration due to its own concept, whereas the wild-sedimentary tributaries with a high slope. Due to also having sedimentation problem through the normal season it is not appropriate to connect them directly to the main channel. In normal times, it has been planned to convey the inflow to an interception pipeline to be located next to the main channel instead of taking into the main channel.

The tributaries having high slopes have been taken into the main channel by conveying the channel with cascades so as to be environmentally sound. While doing this, care also has been taken for the compatibility with the recreation areas.

After the tributaries have been taken into the channels with a proper section in their upstream side, they have been equipped with intake structures and settling ponds at the connection points to the main channel at their downstream side (Fig. 10).

The water taken by the intake structures and the settling ponds will be conveyed into the interception pipeline. The interception pipeline has been located in the right bank of the main channel so as to be also proper for recreation (Fig. 11).



Figure 10: Tributary connection structure. 


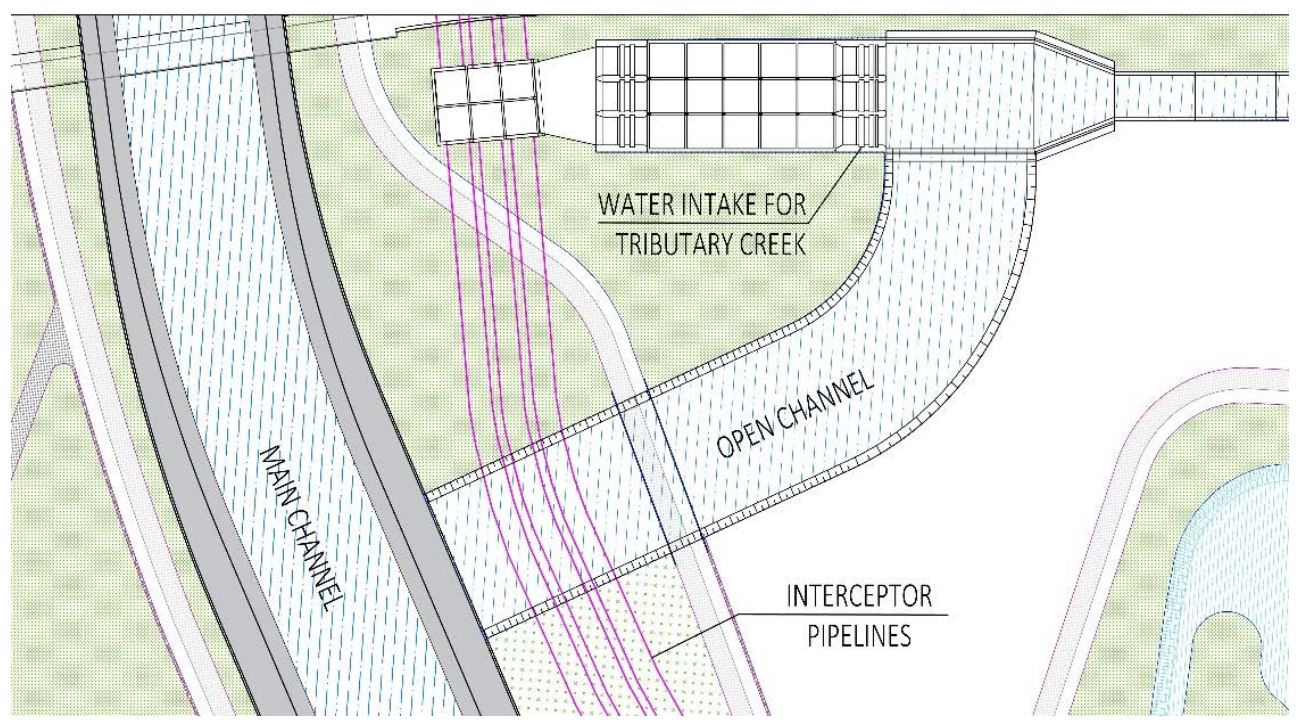

Figure 11: Tributary connection structure.

The intake structures have been equipped with gates. At the flood duration, the tributaries will be closed by the gates by means of the automation system and the flood will be directed to the main channel. In the normal season, the water of creeks will be conveyed into the interception pipeline by means of the intake structure and the settling ponds. In flood season, a side channel spillway has been designed to convey water into the main channel.

A similar system has been also located at the beginning of the main channel (Fig. 12). The suspended sediment carried by the main creek will be conveyed to the interception pipeline via intake structure placed at the beginning of the channel. This control structure is a weir and will be used in order to direct the raised water to the intake structure. It will also trap the washed away sediments that will come in normal season and at the flood times. The capacity of intake structure has been selected based on the minimum frequency flood flow and it will transfer all water up to this flow to the interception pipeline.

\section{RECREATIONAL STRUCTURES}

The Valley Ankara Project will ensure that the abandoned creek in the project area located around the settlement is reclaimed and used as a recreation area. As a result, the project area and surrounding interaction areas will be become liveable and it will raise the economic value of the creek band and the abroad.

The land and location information has been investigated first for the Valley Ankara Project and the maximum land use has been determined as a basic principle in the project area consisting of the natural environment and creek corridor. It will be possible to realize all of these by ensuring the flood safety. The design of the main channel is a primary priority for the creation of a recreation area.

The Valley Ankara Project is located at a very valuable place because it is on one of the important ecological corridors of the city. The project designing performed in the region will not only support the increased biodiversity by enabling the dispersed green area to connect, but the channel to be designed will also ensure the continuity of the open area, the access points, and the pedestrian way network between the recreational landscape structures such as 


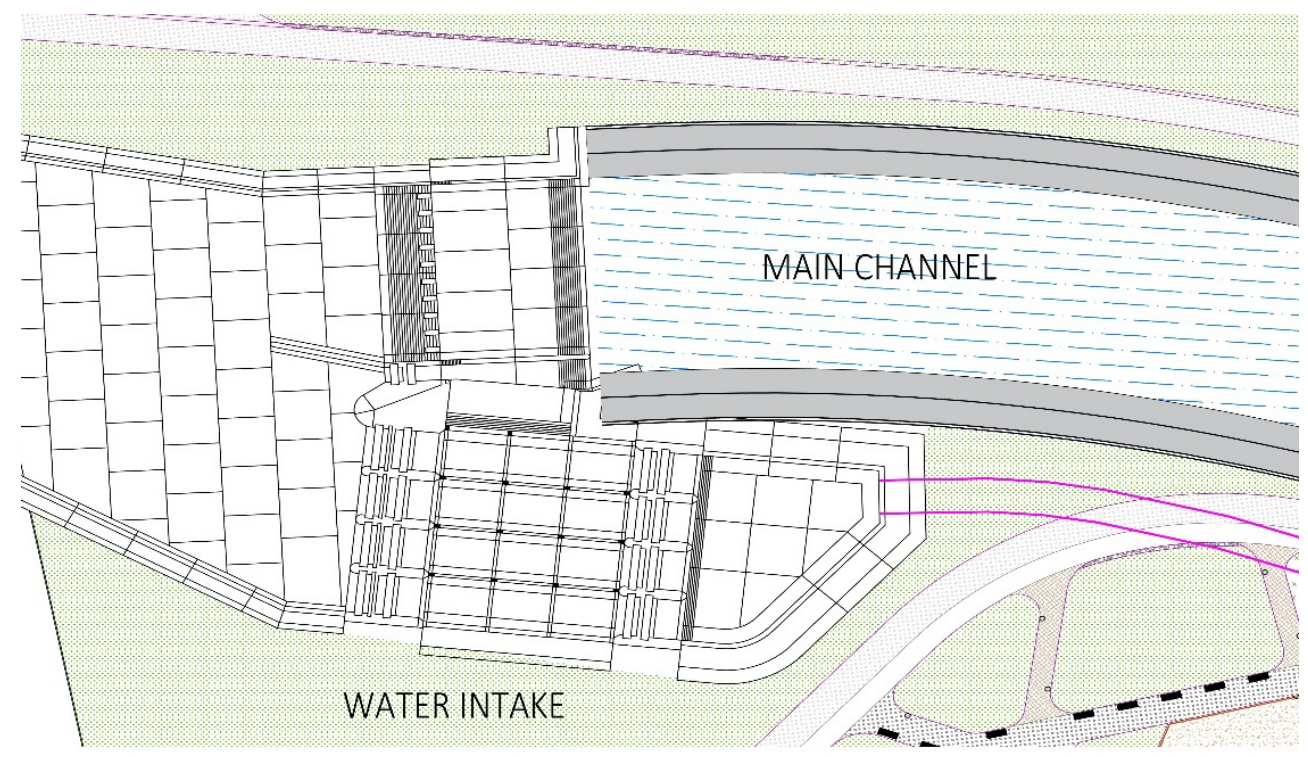

Figure 12: Main river weir, intake structure and settling pond.

artificial ponds and the structures having an architecture specific to the project (cafeteria, restaurants, play areas, service buildings, etc.).

In simple words, the project including the water channel and recreation areas consists of the following conceptual criteria shown in Table 1.

The basic approach is to create a powerful green area in the city. The project has a property of an important recreational center where the inhabitants would get a fresh breath in the midst of intense urbanization and the designed athletic, social, and cultural activity areas will add value to the city (Fig. 13).

Various activity zones have been planned in scope of the foreseen concept during predesign phase (Fig. 14).

In parallel of the understanding of today's modern landscape architecture, the objective is to establish the sustainable areas close to human scale and integrating into surrounding structures, which attract the attention with it spatial value making an impression on user's

Table 1: Conceptual criteria during pre-design stage.

\begin{tabular}{|l|l|l|}
\hline \multicolumn{3}{|c|}{ Conceptual criteria } \\
\hline Regional & Recreational & Living/usage \\
\hline Flood data & Max. recreational land use & Counter urbanization \\
\hline $\begin{array}{l}\text { Climate and } \\
\text { environmental data }\end{array}$ & Interface with green & Integrated with nature \\
\hline Urban infrastructure & Urban design & Live open-space usage \\
\hline Transportation & Modular plan structure & $\begin{array}{l}\text { Elderly, children and disabled- } \\
\text { friendly attraction center }\end{array}$ \\
\hline & Sustainable design & \\
\hline & Aesthetics & \\
\hline
\end{tabular}




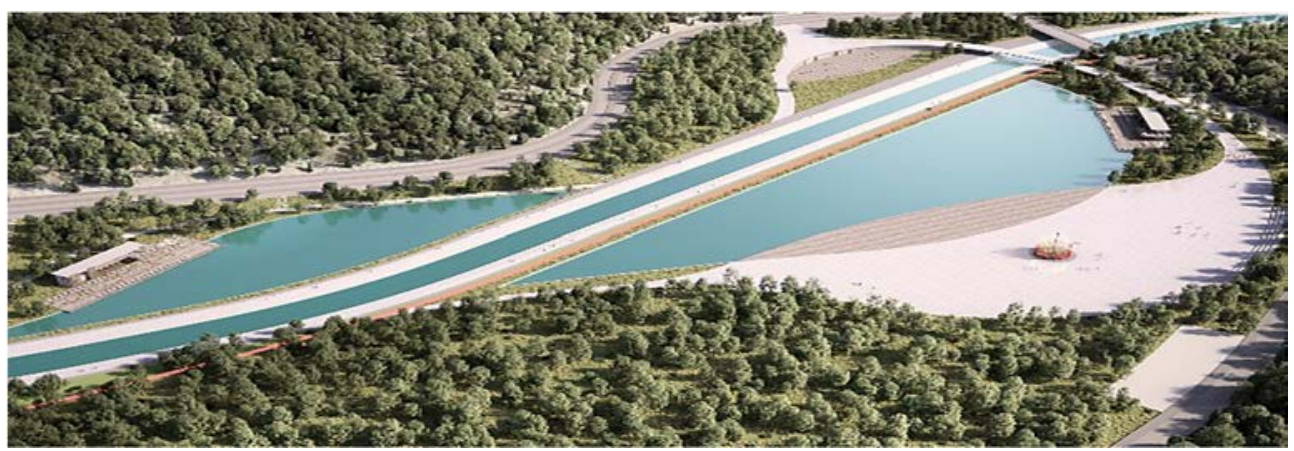

Figure 13: Render of channel after construction.

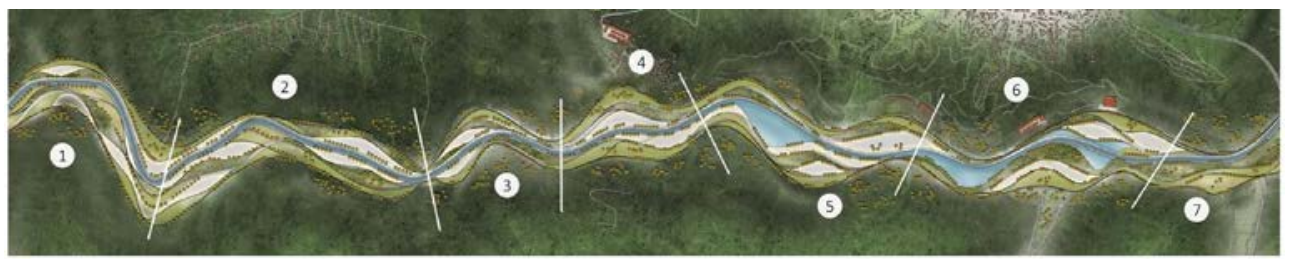

\begin{tabular}{|c|c|c|c|c|c|c|}
\hline $\begin{array}{c}\text { ZONE } 1 \\
\text { NATURAL ZONE }\end{array}$ & $\begin{array}{c}\text { ZONE } 2 \\
\text { SPORT ZONE }\end{array}$ & $\begin{array}{c}\text { ZONE } 3 \\
\text { CULTURAL ZONE }\end{array}$ & $\begin{array}{l}\text { ZONE } 4 \\
\text { COMERIAI }\end{array}$ & $\begin{array}{c}\text { ZONE } 5 \\
\text { CENTRALZONE }\end{array}$ & ZONE 6 & $\begin{array}{c}\text { ZONE } 7 \\
\text { ADVENTURE ZONE }\end{array}$ \\
\hline 1. ECOLOGICAL & & & ZONE & & & \\
\hline $\begin{array}{l}\text { 1. ECOLOGICAL } \\
\text { VUUAGE }\end{array}$ & 1. SPORT AREA & $\begin{array}{l}\text { 1. CONCERT AREA } \\
\text { FESTIVAL AREA }\end{array}$ & 1. COMMERCIAL & 1. MAIN SQUARE & 1. SQUARE & 1. ADVENTURE \\
\hline 2. CAMP AREA & 2. ATLETICS AREA & $\begin{array}{l}\text { 2. FESTIVAL AREA } \\
\text { 3.THEATRE. }\end{array}$ & AREAS & 2. VIEW TERRACE & 2. VIEW TERRACE & PARK \\
\hline 3. WORKSHOPS & 3. FOOTBALL AREA & 4. EXHEBITION & 2. RESTORANT & $\begin{array}{l}\text { 4. GRASS } \\
\text { AMPHITHEATRE }\end{array}$ & $\begin{array}{l}\text { 3. POND } \\
\text { 4. POND FOR }\end{array}$ & 2. CUMBING WALL \\
\hline 4. FRUIT & 4. BASKETBALL & AREA & 4. REST AREAS & 5. POND & WATER EXHAB, & $\begin{array}{l}\text { 3. AUVENIURE } \\
\text { BRIDGE }\end{array}$ \\
\hline GARDENS & AREA & 5. WORKSHOPS & 5. ADMIN. & 6. POND CAFE & $\begin{array}{l}\text { 5. PIER } \\
\text {. }\end{array}$ & 4. FANTASTIC \\
\hline 5. BOTANIC & 5. VOLEYBALL & 6. MUSEUM & BUILDING & 7. POND & 6. POND FOR & GAME AREA \\
\hline GARDENS & AREA & 7. OPEN AIR & & RESTAURANT & MODEL SHIP & 5. ELEC. GAME \\
\hline 6. REST AREAS & 6. TENNIS COURT & CINEMA & & 8. ADMIN. & 7. ICE RINK & AREA \\
\hline 7. CAFE & 7. SCATEBOARD & 8. CAFE & & BUILDING & 8. ADMIN. & 6. ACCESSIBLE. \\
\hline 8. ADMIN. & AREA & 9. ADMIN. & & & BUILDING & GAME AREA \\
\hline BUILDING & 8. CAFE & BUILDING & & & & 7. PAINTBALLAREA \\
\hline & 9. ADMIN. & & & & & 8. ADMIN. BUILDIN \\
\hline
\end{tabular}

Figure 14: Activity zones in the project area.

daily life rather than only the color, decoration or pattern-seeking in public spaces, the users feel the sense of belonging and safe, and they benefit from current technologies, the correct materials and equipment are used.

In line with the opinion that the process of design of modern life and individual's common space can be worked by a "participatory" understanding, it will strengthen the relations and communications of investor-designer-urbanite as well as the designing-planning stage comprising the urbanites offers more quality and constructively sound living spaces at an urban scale.

While the project meets the requirements of urban recreational area by maintaining its natural beauty, it will have a very important mission for creating an attraction power in the region and providing the mixed uses which allow the congress and culture center, which is needed by the city and has an extremely important role in the publicity of city, to be used within the scope of tourism areas. 
This region to create a new urban attraction center encourages the urbanites to be inside it and breathe new life into the city thanks to the activity facilities it provides. The activities placed on the region will be the oxygen resources of the city and urbanites.

\section{CONCLUSIONS}

The carried out studies show that the whole system consists of many components: the flood channel, the chutes and embankments within the channel, the pondlets and water within them, the hydraulic structures at the beginning of the main channel, the interception pipeline for the bypass purpose, the tributaries and their hydraulic structures, the connections of the tributaries to the main channel and the interception pipeline, the compatibility of all these hydraulic components with the recreation, etc. The issue is very complicated and very difficult to make calculations manually. Also, it is misleading to consider the main channel as a stand-alone and dimension it. Similarly, considering the tributaries as a stand-alone and dimensioning them will also provide wrong conclusions. And, it is not also adequate to carry out the hydraulic dimensioning of all these structures. These structures should also create the appropriate recreational areas, not turn into a concrete jungle, attracting all attention to itself in the study area.

Therefore, the system has been examined along with all its elements (the recreational elements, hydraulic components, and subcomponents) and it was necessary to make calculations by also taking into consideration the behaviors of the tributary connections and the main creek intake structures in different scenarios.

\section{REFERENCES}

[1] MIKE 21 Hydrodynamic Module, Step by Step Training Guide, MIKE Documentation Center.

[2] MIKE 11 River and Channel Modelling, Short Introduction Tutorial, MIKE Documentation Center.

[3] King, H.W. \& Brater, E.F., Handbook of Hydraulics, McGraw-Hill Book Co.: New York, 1976.

[4] French, H.R., Open-Channel Hydraulics, McGraw-Hill Book Co.: New York, 1987. 